\section{INJECTING PRESSURES DURING REGIONAL ANAESTHESIA. CAN PRACTITIONERS PREDICT SAFETY OBJECTIVELY?}

'D White*, 'P Young, 'B Fox, '1 Stimpson, ${ }^{2} \mathrm{~S}$ Southey, ${ }^{1} \mathrm{R}$ Heij. ${ }^{1} T$ The Queen Elizabeth Hospital King's Lynn NHS Foundation Trust, King's Lynn, UK; ${ }^{2}$ Catena Consulting, London, UK

\subsection{6/rapm-2021-ESRA.209}

Background and Aims Nerve injury is a rare but well-known complication of regional anaesthesia and may arise from high pressure administration of local anaesthetic directly into nerve fascicles.

Safe injection pressures $\left(<20\right.$ psi) ${ }^{1,2}$ are subjective to estimate with manual injection, and this task is often delegated to skilled assistants. Pressure-limiting injection devices such as SAFIRA $^{\circledast}$ (Medovate, UK) have been designed to reduce this risk.

This study measures injection pressures deemed 'safe' by experts and compares them with that of SAFIRA ${ }^{\oplus}$.

Methods Following IRB approval and with consent, ten skilled Operating Department Practitioners (ODPs) and ten Anaesthetists were recruited to inject $0.9 \%$ Saline at the highest pressure they thought safe' using a series of syringes $(2.5 \mathrm{ml}, 5$ $\mathrm{ml}, 10 \mathrm{ml}, 20 \mathrm{ml}$ and $50 \mathrm{ml}$ ) attached to a Fluke $700 \mathrm{GO} 6{ }^{\oplus}$ pressure transducer (Fluke Corp, WA, USA). One hundred measurements were recorded.

We then attached the SAFIRA ${ }^{\circledR}$ device (fitted with a $20 \mathrm{ml}$ syringe) to the pressure transducer and measured the machinelimited pressure 100 times for comparison.

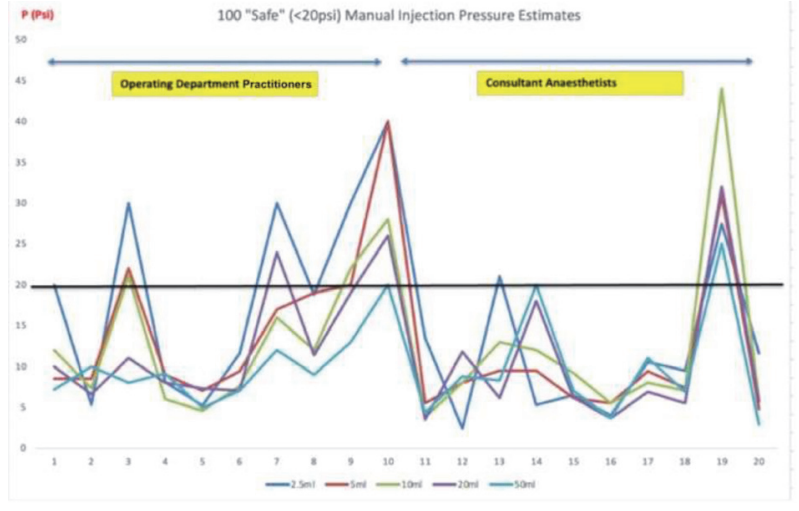

Abstract 209 Figure 1

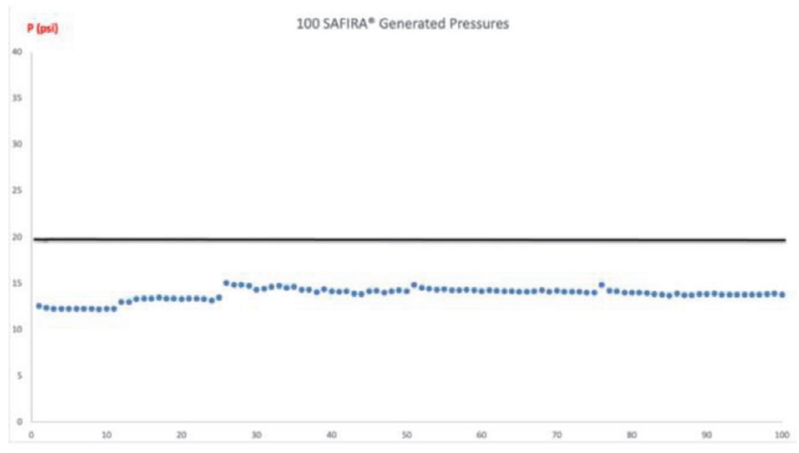

Abstract 209 Figure 2

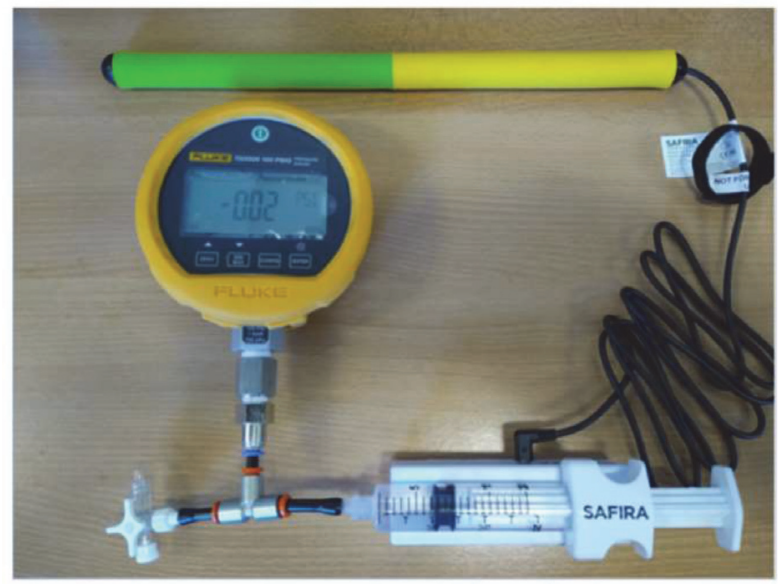

Abstract 209 Figure 3

Results In 21/100 manual injections, estimated 'safe' pressure was exceeded, with the highest measured at 44psi.

Though the data was skewed by a few individuals, $50 \%$ of ODPs and $30 \%$ of Anaesthetists injected at pressures $\geq 20 \mathrm{psi}$ at least once (at all syringe sizes).

Cut-off pressures from SAFIRA ${ }^{\oplus}$ were consistently below 20psi.

Conclusions Practitioners best estimates of safe manual injection pressure is inaccurate. In contrast, a calibrated and engineered solution such as SAFIRA $^{\circledast}$ does not require subjective user estimation.

\section{APPLICATION OF PERIPHERAL NERVE BLOCK ON A PATIENT WITH MULTIPLE SCLEROSIS}

F Özdemir, Ü Yaman, ÜA Türkmen, S Soylu*. T.C Sbü Gaziosmanpașa Education and Research Hospital, Istanbul, Turkey

\subsection{6/rapm-2021-ESRA.210}

Background and Aims Multiple Sclerosis (MS) is an autoimmune disease of the Central Nervous System (CNS) In our case, we present our anesthesia management applied on a MS patient. Our patient was 47 years old, $167 \mathrm{~cm}$ tall, $75 \mathrm{~kg}$ female and has been diagnosed with MS for 20 years. She had a left ankle fracture and had lower extremity surgery. Methods After visualizing the sciatic nerve in sub-gluteal region with a linear US probe in lateral decubid position, the neurostimulator was started at $2 \mathrm{~Hz}$ frequency at stimulation level of $0.8 \mathrm{~mA}$ with $0.1 \mathrm{~ms}$ intervals. When motor response was seen, the stimulation level was reduced to $0.4 \mathrm{~mA}$. When motor response disappeared, $20 \mathrm{ml}$ of $0.5 \%$ Bupivacaine hydrochloride $(100 \mathrm{mg})$ was administered around the sciatic nerve with an $80 \mathrm{~mm}$ block needle. Afterwards, the patient was put in supine position. $15 \mathrm{ml}$ of $0.5 \%$ Bupivacaine $(75$ mg) was administered around the femoral nerve. Motor and sensory tests were applied 30 minutes after the procedure. Her vitals remained stable throughout the surgical operation. She was discharged to the orthopedic service.

Results When a nondepolarizing muscle relaxant is used, resistance or sensitivity has been observed as a result of proliferation of extra-connective cholinergic receptors due to upper motor neuron plaques (3). Most of the limited studies, support US-guided peripheral nerve blocks in MS and report that 